\title{
Trayectorias personales de jóvenes con experiencias familiares de inmigración
}

\author{
Obiane Ojeta \\ DAFITS, Universitat Rovira i Virgili \\ ohiane.ojeta@estudiants.urv.cat
}

Resumen: El presente artículo es un breve resumen de los principales aspectos tratados en el trabajo de fin de máster, donde se analizan las experiencias de vida de varios jóvenes que han experimentado procesos familiares de inmigración y que actualmente residen en nuestro país.

Mediante el análisis de las entrevistas en profundidad y el análisis de redes, se realiza una aproximación a los recorridos y trayectorias vitales de cinco jóvenes de origen marroquí. Dándoles el mayor de los protagonismos, trataremos varios de los temas clave discutidos y trabajados en la presente investigación, relacionados directamente con sus percepciones y experiencias de vida en nuestra sociedad.

Palabras clave: migraciones; redes; identidad; juventud; experiencias de vida.

Abstract: The present article is a brief summary of the main aspects dealt with in the author's master's thesis, which analysed the life experiences of various young people who have experienced family processes of immigration and who currently live in Spain.

The article undertakes an in-depth analysis of interviews with five young Moroccans to determine their life stories and the nature of their support networks. Keeping the young people at the centre of the investigation, the article deals with various key themes that featured in the master's thesis and which are directly related to their perceptions and life experiences in Spanish society.

Key words: migrations; networks; identity; youth; life experiences. 


\section{Introducción}

El fenómeno migratorio implica cambios y transformaciones sociales, económicas, políticas y personales. Con el asentamiento de grupos de población de origen extranjero han emergido nuevas necesidades sociales, nuevas realidades y prismas desde los que enfocar nuestra propia vida cotidiana. Estas nuevas realidades se acogen a la diversidad tanto de ser como de pertenecer y vivir nuestro entorno más inmediato. Esta problemática constituye el contexto en el que se forja nuestro interés por el estudio de los jóvenes hijos e hijas de inmigrantes.

Los recientes acontecimientos terroristas en Francia ${ }^{1}$ han abierto un nuevo debate relacionado con la inmigración en Europa. En consecuencia, han (re) emergido temas como la integración de los hijos e hijas de inmigrantes ${ }^{2}$. En esta línea, la importancia que estos temas han adquirido en muchos de los discursos políticos actuales deja entrever muchas fracturas sociales que se han intentado maquillar hasta el momento.

En el presente artículo se abordarán los aspectos relacionados con las experiencias de vida de varios jóvenes de origen marroquí residentes en Tortosa (Cataluña). Todos estos jóvenes comparten una particularidad muy concreta: han experimentado un proceso familiar de inmigración, es decir, ninguno de ellos (como otros muchos jóvenes que emigran siguiendo la vía de la reagrupación familiar) ha formado parte activa de la decisión de migrar. Esta particularidad me suscitó la curiosidad que ha encaminado este trabajo: ¿qué papel desempeña la migración en el vivir cotidiano de estos jóvenes?? ¿y en sus maneras de percibir, sentirse e identificarse?, ¿cómo deberíamos acercarnos a ellos, desde qué ópticas y en qué términos?, ¿de qué manera influye una educa-

1 Los atentados de París del 13 de noviembre de 2015 consistieron en varios ataques terroristas que inundaron la capital francesa de terror. Perpetrados por varios atacantes suicidas, fallecieron 140 personas y otras 415 resultaron heridas. Los ataques se realizaron simultáneamente en diferentes puntos de París, en los alrededores de Rue de la Fontaine-au-Roi, Rue de Charonne y en el teatro Bataclan. La autoría de los ataques fue reivindicada por la organización yihadista Estado Islámico (Europa Press, 2015. «Al menos 140 muertos por cinco ataques simultáneos en París», de Europa Press. [Consultado el 10 de marzo de 2016]. Sitio web: $<$ http://www.europapress.es/internacional/noticia-varios-heridos-tiroteo-paris-20151113222405.html>).

2 Recordemos los disturbios ocurridos en Francia en el año 2005, los cuales comenzaron tras la muerte de dos adolescentes (17 y 15 años) musulmanes de origen africano mientras escapaban de la policía en una banlieue («suburbio») del este de París. Estos disturbios se caracterizaron por la quema de millares de coches y por violentos enfrentamientos con la policía francesa. (El Mundo, 2005: «Los disturbios en Francia, día a día». [Consultado el 10 de marzo de 2016]. Sitio web: <http://www.elmundo.es/elmundo/2005/11/04/ sociedad/1131110014.html>). 
ción «en dos culturas»?, ¿̇y cómo es esta educación?, ¿̨cuáles son sus principales redes personales?, ¿`ómo son sus relaciones personales y sociales?... El objetivo principal del presente trabajo, por lo tanto, es conocer las experiencias de vida de estos jóvenes. Si bien se explica en profundidad a lo largo del ensayo, podemos avanzar que todos los participantes llegaron a España a los pocos meses o años de nacer, y en lo que a la situación administrativa y legal respecta, los hay con nacionalidad española y también quienes se encuentran tramitando dicha solicitud.

\section{2. «Hijos e hijas de inmigrantes» en España}

Las realidades y experiencias de vida de los «hijos e hijas de inmigrantes» se han visto en su mayoría desde una lógica de integración o exclusión en nuestras sociedades. De hecho, los antecedentes en el estudio de estos jóvenes muestran que el interés ha recaído más en las instituciones o en los gobiernos y, en consecuencia, en las medidas sociopolíticas adoptadas, que en las personas inmigrantes o sus hijos y las habilidades o competencias que puedan tener para facilitar dicha integración.

A partir de los años noventa, junto con el aumento de los flujos migratorios, las investigaciones sobre la incorporación de los inmigrantes en las sociedades de acogida aumentan y empiezan a ser más significativas y complejas. Paralelamente, las investigaciones sobre los «hijos e hijas de inmigrantes» empiezan a incorporar nuevos temas de interés, sobre todo relacionados con la integración escolar, la atención a la diversidad o la adopción de medidas específicas en respuesta a la situación multicultural de los centros educativos (Portes y Aparicio, 2014). Con el tiempo, las investigaciones empiezan a contar con datos más depurados y precisos relacionados específicamente con la situación de estos «hijos de inmigrantes», y cubren así diversos aspectos de su realidad, como, por ejemplo, sus expectativas educativas y sociales, la discriminación padecida en los centros de enseñanza, su integración en los centros, la evolución identitaria o las amistades de los jóvenes (Portes y Aparicio, 2014).

De esta manera, la aproximación a la realidad de estos jóvenes empieza a salir de la lógica de integración y exclusión. Partiendo de una concepción de la integración social no como una meta en sí misma, sino como un proceso vital, una manera de vivir y ser percibido en la sociedad, es de crucial impor- 
tancia dar voz a quienes experimentan esta situación vital, y adentrarnos en todo el entramado que es el juego de la vida.

En esta línea, es necesario reflexionar sobre cómo y de qué manera nos acercamos a estos jóvenes «inmigrantes». En los últimos años ha emergido un debate conceptual sobre el uso de los términos generación o segunda generación e hijos e hijas de inmigrantes. La connotación y el énfasis de su uso han ido cambiando también con el tiempo. En lo que al primero respecta, es un término que parte de un supuesto de naturalización mediante el cual se asigna la condición de migrante a alguien que o bien ha nacido ya en el país, y que por lo tanto debería considerarse ciudadano de aquel país, o bien ha llegado mediante un proyecto migratorio familiar y a temprana edad. No obstante, el uso de hijos e hijas de inmigrantes se aleja de este supuesto de biologización y pone más el énfasis en los propios hijos e hijas y no en la condición familiar de inmigrantes.

Aun así, y con relación a los objetivos de este trabajo, creo imprescindible no utilizar ninguna de las dos expresiones, y centrar y ajustar la mirada en la condición más importante que comparten, la de jóvenes con una particularidad en común: tener una experiencia personal o familiar de inmigración. Es decir, es importante intentar ver su condición como una particularidad que comparten varios jóvenes de nuestro país, y que, como tal, es necesario aproximarnos a ellos desde esta perspectiva. Es necesario reajustar el prisma y la mirada desde la cual nos acercamos y nos dirigimos a estos jóvenes, ya que son ellos quienes pueden verse afectados por tales formas segregacionistas de percibir su realidad. La migración desempeña un papel verdaderamente importante en el día a día de estos jóvenes y en cómo perciben y viven su realidad. Sus experiencias vitales caminan entre dos formas de ver, sentir y percibir la vida: por un lado, sus padres siguen manteniendo prácticas, costumbres y valores de su país de origen, que pasarán a los hijos por diversos motivos, generalmente pensando en un posible retorno al país de origen; y por otro lado, estos jóvenes incorporan nuevos elementos y valores propios de nuestra sociedad. La visión del mundo de estos jóvenes, por tanto, se conforma por la adhesión de elementos de ambas culturas, que darán a cada uno su particular manera de sentir y vivir su vida cotidiana. 


\section{Consideraciones metodológicas}

Esta investigación ha seguido una aproximación cualitativa con el fin no solo de describir, sino también de profundizar en el conocimiento de cuáles y cómo son las experiencias de vida de jóvenes que, en este caso, comparten una particularidad concreta: tener una experiencia familiar de inmigración. El objetivo principal, por lo tanto, ha sido dar voz a esos jóvenes, y poder así entender el sentido y la experiencia de sus vidas. En esta línea, Pujadas (2010: 70) apunta que «zambullirse en la subjetividad de las vidas cotidianas de los informantes es lo que nos permite encontrar el sentido, comprender lo que mueve y orienta las prácticas sociales y la cotidianidad de las personas». El uso de la etnografía, en este caso, me ha permitido acercarme más en profundidad a cada trayectoria personal, tal y como ellos las relatan, dándome la posibilidad de distinguir y describir estas de una manera más personal. La evolución de la investigación se caracteriza por seguir una lógica flexible e inductiva, es decir, es a partir del contacto con los informantes y de la información que aportan como se (re)interpretan y relacionan los diferentes conceptos y teorías.

La investigación cualitativa, como apunta Corbetta (2007: 41), está inspirada en el paradigma interpretativo, por lo que «la relación entre teoría e investigación es abierta, interactiva». La teoría surge, en este caso, a partir de un trabajo de campo y de la recogida de diferente información que hace emerger nuevas cuestiones que enmarcar y que contextualizar. Este método inductivo estaría, además, relacionado con un planteamiento flexible de la investigación. Como apunta Nora Mendizábal (2006:67), «el concepto de flexibilidad alude a la posibilidad de advertir durante el proceso de investigación situaciones nuevas e inesperadas vinculadas con el tema de estudio, que puedan implicar cambios en las preguntas de investigación y los propósitos». Varios de los objetivos de esta investigación han sido modificados una vez comenzado el trabajo de campo: es evidente que proyectar y mantener unos objetivos sobre el papel no es lo mismo que abordarlos en la acción, en la puesta en marcha, in situ. Nuevas preguntas han emergido también a medida que los informantes aportaban información, las cuales han sido incorporadas posteriormente.

Mi aproximación y relación con el objeto de estudio se da en el propio contexto de los jóvenes, en Tortosa, y soy yo la que me sumerjo en su realidad. En este caso, las técnicas utilizadas, como las entrevistas en profundidad y el análi- 
sis de redes, adjudican un papel protagonista a los informantes, que son sujetos activos del proceso. Los criterios para la selección de los informantes fueron los siguientes: jóvenes entre 15 y 21 años; interesados en participar y colaborar en la investigación; haber experimentado un proceso familiar de inmigración; de ambos géneros; y diversidad de situaciones ocupacionales:

\begin{tabular}{|c|c|c|c|c|c|c|}
\hline Informante & Edad & Género & Ocupación & $\begin{array}{l}\text { Proyecto } \\
\text { migratorio }\end{array}$ & $\begin{array}{l}\text { Situación } \\
\text { administrativa }\end{array}$ & Observaciones \\
\hline Jibril & 18 & Hombre & $\begin{array}{l}\text { Estudiante de } \\
\text { Bachillerato }\end{array}$ & $\begin{array}{l}\text { Reagrupación } \\
\text { familiar }\end{array}$ & $\begin{array}{l}\text { Tiene la doble } \\
\text { nacionalidad } \\
\text { (Marruecos/ } \\
\text { España). }\end{array}$ & $\begin{array}{l}\text { Llegó a } \\
\text { Tortosa a los } \\
\text { pocos días de } \\
\text { nacer. }\end{array}$ \\
\hline Moha & 21 & Hombre & - & $\begin{array}{l}\text { Reagrupación } \\
\text { familiar }\end{array}$ & $\begin{array}{l}\text { Los papeles para } \\
\text { la obtención de la } \\
\text { doble nacionalidad } \\
\text { están en trámite. }\end{array}$ & $\begin{array}{l}\text { Llegó a } \\
\text { Tortosa } \\
\text { cuando tenía } \\
10 \text { años con } \\
\text { sus hermanos } \\
\text { y su madre. }\end{array}$ \\
\hline Nadia & 19 & Mujer & - & $\begin{array}{l}\text { Reagrupación } \\
\text { familiar }\end{array}$ & $\begin{array}{l}\text { Los papeles para } \\
\text { la obtención de la } \\
\text { doble nacionalidad } \\
\text { están en trámite. }\end{array}$ & $\begin{array}{l}\text { Lleva viviendo } \\
\text { en Tortosa } 12 \\
\text { años. Llegó } \\
\text { con el resto de } \\
\text { hermanos y su } \\
\text { madre. }\end{array}$ \\
\hline Samira & 18 & Mujer & $\begin{array}{l}\text { Estudiante de } \\
\text { Grado Medio } \\
\text { de Gestión } \\
\text { Administrativa }\end{array}$ & $\begin{array}{l}\text { Reagrupación } \\
\text { familiar }\end{array}$ & $\begin{array}{l}\text { Todavía no ha } \\
\text { cumplido los } 10 \\
\text { años de residencia, y } \\
\text { no puede optar a la } \\
\text { doble nacionalidad. }\end{array}$ & $\begin{array}{l}\text { Llegó a } \\
\text { Tortosa en } \\
\text { 2006, cuando } \\
\text { tenía } 9 \text { años. } \\
\text { Vino con su } \\
\text { hermana y su } \\
\text { madre. }\end{array}$ \\
\hline Khadija & 16 & Mujer & $\begin{array}{l}\text { Estudiante de } \\
4 .^{\circ} \text { de ESO }\end{array}$ & $\begin{array}{l}\text { Reagrupación } \\
\text { familiar }\end{array}$ & $\begin{array}{l}\text { Todavía no ha } \\
\text { cumplido los } 10 \\
\text { años de residencia, y } \\
\text { no puede optar a la } \\
\text { doble nacionalidad. }\end{array}$ & $\begin{array}{l}\text { Vino a } \\
\text { Tortosa } \\
\text { cuando tenía } 8 \\
\text { años junto con } \\
\text { su hermano } \\
\text { mayor y su } \\
\text { madre. }\end{array}$ \\
\hline
\end{tabular}


A raíz de mi estancia de prácticas en $\mathrm{ACISI}^{3}$, establecí relación con varias personas que trabajan $y$ viven en Tortosa, y que conocen muy de cerca la sociedad tortosina. Dos de estas personas han sido claves para establecer contacto y mantener las entrevistas con los informantes, ya que, debido a que también proceden de Marruecos, conocen muy de cerca tanto a los informantes como la propia realidad y las dinámicas que viven. Todos los jóvenes entrevistados han formado parte de ACISI, en proyectos de diferente índole impulsados en la ciudad de Tortosa. Entre estos proyectos encontramos TAMUNT, proyecto que promueve la transformación personal y social de jóvenes de 16 a 25 años en el ámbito de la identidad, los sentimientos de pertenencia, la convivencia y la participación, para provocar sinergias individuales y colectivas hacia la mejora de la convivencia ciudadana intercultural en los ámbitos de la escuela, el barrio y el entorno natural. Todos los informantes se conocen entre ellos, y aunque compartan más o menos hábitos diarios, comparten la misma realidad cotidiana.

\section{Trayectorias personales}

Los cinco participantes muestran trayectorias similares, pero cada una de ellas es en sí misma particular y única. Las diferencias más significativas giran en torno al tiempo que llevan en España y al género, ya que observamos que las trayectorias de los chicos y de las chicas difieren en cuanto a la vida $y$ las expectativas y planes de futuro. Excepto Samira, que vivía en Kenitra, una ciudad al noroeste de Marruecos, el resto de los jóvenes vivían en zonas rurales, rodeados de campos, prados y, como señala Jibril, animales y ganaderías.

Este apartado se desarrolla en cinco puntos temáticos clave tratados a través de las entrevistas en profundidad, y complementadas con la visualización de las redes personales: sus proyectos vitales; la familia; la religión; la escuela; y las amistades o sociabilidad de calle.

3 La Asociación por la Cooperación, la Inserción Social y la Interculturalidad (ACISI) se creó en 1999 con el objetivo de trabajar conjuntamente con otras entidades públicas o privadas en ámbitos como la cooperación, el codesarrollo, la acogida o la inserción social, siempre desde una perspectiva intercultural y buscando la cohesión social (<http://acisi.org/benvinguts/presentacio/ >). 


\subsection{Proyectos vitales}

Todos los participantes muestran unas expectativas claras y varias ideas de futuro. Ninguno se imagina construyendo su proyecto vital en Tortosa, sobre todo por la actual situación económica española. Explican que esta situación les frustra bastante y, reproduciendo la migración familiar, vuelven a plantearse emigrar en busca de empleo y de un futuro mejor. Si bien a la mayoría les gustaría permanecer cerca de su familia en Tortosa, esto no impide una proyección de vida en otros lugares. Por otro lado, dejan claro que tampoco volverían a vivir a Marruecos, ya que precisamente allí la situación no es mejor que en España, si no fuera para permanecer allí el resto de sus años de vida.

Yo estoy pensando que, cuando sea mayor, cuando sea abuelita o algo, pues sí que me gustaría vivir allí toda mi vida, porque me gustaría morir allí, con mi tierra... (Nadia)

En general, proyectan su futuro en otros países de Europa, donde buscarían un empleo acorde con su formación, algo ideal para todos ellos. No obstante, les cuesta imaginar empezar de cero otra vez y reincorporarse en otra sociedad o aprender otra lengua: son estos los principales motivos que les hacen replantearse irse o no de Tortosa.

Ahora mi preferencia es buscar trabajo... porque pedir dinero a mis padres con 21 años [...]; dentro de diez años seguramente no me vas a encontrar aquí... Igual estaré en otro país, que se pueda vivir mejor... (Moha)

Existen diferencias relevantes según el género de los participantes. La mayor prioridad de las chicas es ser madre joven y formar una familia, mientras que los chicos ni siquiera mencionan el tema y se centran más en encontrar un empleo y buscar una estabilidad laboral.

Mis planes son casarme y tener hijos. Quiero ser madre y hacer un buen futuro a mis hijos... Que no les falte nada. Que sean mejor que yo... (Nadia)

En general, por lo tanto, los planes de futuro giran en torno a la búsqueda de un futuro estable, con trabajo y con la familia. 


\subsection{Los orígenes y la familia}

A excepción de Jibril, que llegó a los pocos días de nacer, el resto de los jóvenes tienen diversos recuerdos y sensaciones de cómo era su vida en Marruecos. Como vinieron siendo niños, los detalles de su vida allí se difuminan y forman parte de anécdotas, recuerdos propios y relatos familiares. Los cinco acostumbraban a vivir junto con su familia extensa, por lo que la convivencia estaba abierta a más miembros de la familia. En cierto modo, el hecho de compartir casa con tantas personas ha sido uno de los motivos para buscar oportunidades de vida o un mejor empleo para poder vivir más tranquilos.

Los cinco jóvenes han llegado a Tortosa a raíz de un reagrupamiento familiar. Es decir, en todos los casos el padre ha sido el primero en marchar y emigrar de Marruecos, con destino, por lo general, a Francia, donde tendrían, por un lado, más contactos, y por otro, más facilidades en cuanto a la lengua, lo cual les permite comunicarse mejor. Después de pasar algunos años en Francia, las oportunidades laborales les llevaron a conseguir empleo en Tortosa, donde además obtendrían el permiso de reagrupación familiar y se asentarían con el resto de la familia. Hay quien ha venido directamente a Tortosa a trabajar también. Todos los entrevistados, por lo tanto, llegaron directamente a Tortosa junto con su madre y algún hermano o hermana, y aquí se encontraron con el padre. Con el paso de los años, hay familias que han ido aumentando, con hermanos nacidos ya en Tortosa.

Al nacer yo mi padre estaba en Francia, tenía nacionalidad francesa porque había ido allí a trabajar [...], luego consiguió aquí empleo y vine con mi padre, mi madre y mis cuatro hermanos [...], siempre he vivido en Tortosa. (Jibril)

La primera sensación al llegar fue una mezcla de alegría, por el hecho de reencontrarse con sus padres después de tantos años, y de angustia, por vivir una etapa nueva. El cambio de lugar, de gente, de idioma, de hábitos y demás, los dejó boquiabiertos en primera instancia, pero el hecho de venir tan jóvenes ha sido un punto a favor para la incorporación y adaptación a este nuevo contexto. Por lo general, todos intuían que algún día viajarían donde estaba su padre $y$, por lo tanto, han podido hacerse una idea de qué y cómo sería el lugar que les esperaba. Eso sí, esta idea, en la mayoría de los casos, no se ha cumplido: 
Me lo imaginaba como que iba a vivir en una gran ciudad, en una casa supergrande, con criadas... ¿ ¿Sabes? ¡Me lo imaginaba así! Y cuando vine me he quedado... Digo... ¿vamos a vivir aquí?... Me lo imaginaba de otra manera... Pensaba que era muy diferente... (Khadija)

A día de hoy, parte de la familia con la que compartían casa y el día a día en Marruecos, su familia extensa, ya no está en su entorno más inmediato y la mayoría sigue viviendo en Marruecos, si bien la familia de Samira se instaló en Francia ya hace varios años. Esto ha supuesto un cambio importante en la vida de los jóvenes, un cambio que describen como positivo por pensar que el hecho de estar aquí es vivir mejor y tener más oportunidades en el futuro.

Vinieron siendo niños y ahora son jóvenes que aspiran a seguir buscando un futuro mejor, tanto para ellos como para sus futuras familias. Las relaciones familiares, por lo general, son buenas, correctas, y para algunos incluso algo limitadas. Es decir, quieren a sus padres, y son pilares fundamentales en sus vidas, pero no son referentes en cuanto a amistad, ya que la mayoría admite no contarles sus cosas personales o íntimas. Además, definen al padre como una persona más autoritaria, y tener una relación de confianza con el padre les cuesta aún más.

Está mi padre y es todo a rajatabla. Todos nos portamos bien, hacemos las cosas..., es como se tiene que hacer [...]. Mi padre es el típico padre casi militar que... A ver, mi padre, mi abuelo, que en paz descanse, era un hombre sabio, pero muy duro. Sus lecciones se las enseñaba a sus hijos. Esto no lo hagas así, porque pasa esto y pasa lo otro..., y estas lecciones, claro, eran duras, porque mi padre, digamos, estudió hasta finales de la ESO por decir algo... y lo tuvo que dejar para ir a trabajar. Y... claro, eso influyó mucho en la forma de ser [...]. Siempre tenemos alguna cosa, pero la relación es muy buena... (Jibril)

La rebeldía y la dejadez o el cuestionamiento en seguir varias prácticas básicas de la tradición musulmana, del islam, es uno de los motivos que pueden incentivar y paralizar un avance y un mayor vínculo con sus padres. Todos, ya sea de una manera u otra, viven y sienten una contradicción constante en su forma de vida. Sienten que la familia les exige que actúen como si vivieran en Marruecos, pero se sienten tanto parte de una sociedad como de la otra. 
En definitiva, los participantes llevan prácticamente la mitad de sus vidas viviendo en Tortosa, e incluso Jibril toda su vida. Comparten una llegada agridulce, llena de ilusión y expectativas, pero también de extrañeza de ser y pertenecer a un ambiente totalmente desconocido para ellos. Ahora, este nuevo entorno forma parte de sus vidas, de una redirección de caminos adoptados, de una vida que vuelve a proyectar nuevas expectativas, preocupaciones y planes de futuro.

\subsection{Religión}

Como comentábamos anteriormente, este tipo de contradicciones y ambivalencias son el pan de cada día de jóvenes que viven bajo dos culturas o dos educaciones a veces divergentes. La gran mayoría afirma que no se habría cuestionado el rezar, el beber alcohol e incluso el ponerse el pañuelo si siguieran viviendo en Marruecos.

Yo, tradiciones que hay en el islam de no comer cerdo, de beber cerveza o algún tipo de alcohol..., estas yo las cumplo. Pero eso de rezar las cinco veces... antes lo hacía, pero como llegaron exámenes y me iba a dormir tan tarde... que a veces me olvidaba y eso afectaba mucho. Eso influía mucho y decidí que cuando acabe esta etapa de exámenes y todo ya me centraré en mis creencias. (Jibril)

La vida cotidiana, respecto a la práctica religiosa, en Tortosa la viven diferente, ya que la rutina y los quehaceres se han modificado respecto a cómo se desarrollan en Marruecos. A pesar de eso, los entrevistados revelan que la religión por sí sola, sin la práctica, los define, que es fundamental en sus vidas, o incluso que es su vida.

Para mí es fundamental (el islam)... No sé, porque si tengo la religión, me siento segura..., confío más, la verdad, confío mucho, mucho, y pues cuando quiero hacer algo, pues siempre confío en él y digo que voy hacer esto y que me saldrá bien..., o que bueno... muchas cosas... (Nadia) 


\subsection{El paso por la escuela}

El viaje a Tortosa y el cambio de lugar de residencia ha tenido como consecuencia una disminución, en cierta manera, del ritmo de aprendizaje iniciado en origen, revelando alguna dificultad de aprendizaje relacionada con el cambio de lengua, y sus derivados, como la posibilidad de comunicación (en un apartado posterior tratamos este tema con más profundidad).

La mayoría cuenta que la incorporación al colegio fue difícil, ya que no conocían el idioma y les costaba comunicarse y expresar lo que sentían y pensaban en clase. Aun así, el paso por el aula de acogida les permitió un proceso de aprendizaje de acuerdo a la situación que vivían. En esta aula el grupo era bastante homogéneo en cuanto a sus integrantes, ya que la mayoría procedía de Marruecos. No obstante, acudían también algunos españoles con necesidades especiales (lo cual requiere de una atención más personalizada) y rumanos, entre otros. Los comentarios y relatos positivos con relación al aula de acogida demuestran que su paso por ella amortiguó y facilitó la incorporación al colegio y los ayudó a afrontar la soledad y el duelo de pérdida de sus amigos y amigas de Marruecos:

Las clases, por ejemplo, hablas, no sabías qué decir... no lo entendía lo que hacían... lo que hacía era si había algún chico o chica de mi país pues me lo traducía. Iba también a un aula de acogida, y ahí pues nos enseñaban [...], había gente diferente, rumanos, de aquí también, marroquíes..., Uruguay [...], cuando no sabes hablar te sientes sola... y a lo mejor dicen cosas de ti y tú no te enteras. (Nadia)

Poco a poco, los jóvenes reconocen que el colegio es satisfactorio para ellos, ya que, además, es en él donde conocen a la mayoría de sus amistades y empiezan a formar parte de un grupo. El paso por el aula de acogida les permite relacionarse con mayor soltura y confianza, pero puede implicar otro tipo de rechazo por parte del resto del alumnado en los diversos espacios del colegio, ya sea el patio o la clase ordinaria:

¡Cuando he venido he pasado los peores años de mi vida! De cuarto a sexto de primaria, bueno a primero de ESO, también, pero... [...], los españoles eran muy racistas o no sé, pero me trataban muy mal... me tenían manía... porque era la única marroquí de clase... me trataban muy mal, me pegaban y todo. 
Salía del colegio y uno me cogía la mochila por ahí, otro me daba una leche, otro... no sé, ¿sabes? (Khadija)

Excepto Khadija, que tiene 16 años, el resto de los entrevistados han terminado la ESO e incluso han estudiado un Grado Medio, como es el caso de Samira y Moha. Jibril, con la intención de ir a la universidad, cursa el bachillerato, y Nadia actualmente no estudia. El abandono escolar a causa de las dificultades y problemáticas dadas en el colegio, por lo tanto, no es en estos casos una opción y una salida de emergencia, sino todo lo contrario, les gusta estudiar, y a todos les gustaría encontrar un empleo relacionado con su trayectoria académica.

\subsection{Sociabilidad de calle}

Los relatos de los jóvenes apuntan a que la amistad, los amigos, son parte fundamental de sus vidas. No es de extrañar que, en esta fase vital como es la juventud, los amigos tomen una fuerza considerable en el transcurso de sus vidas. Tanto para los chicos como para las chicas, estar con los amigos es la mayor afición, con diferencias claras entre el tipo de actividades que realizan los unos o las otras. No obstante, en general, el círculo más próximo a ellos lo conforman personas con las que comparten la misma experiencia migratoria $y$ procedencia. Todos coinciden en no identificarse y en no compartir tantas cosas con los jóvenes autóctonos, y se autoidentifican como marroquíes.

A pesar de responder de forma contundente que se sienten marroquíes, si se profundiza más en el tema de la identidad, se observa cierta flexibilidad, ya que admiten la posibilidad de responder que son españoles según en qué circunstancias o en qué contexto se encuentren, por ejemplo en otro país. En este sentido, Levitt y Glick (2004: 69) apuntan que «las personas cambian y se inclinan hacia un lado u otro dependiendo del contexto, y se distancian, así, de la expectativa respecto a ser asimilados — plenamente - o de la completa conexión transnacional, para dirigirse hacia una mezcla de ambas». Además, esta flexibilidad identitaria, sentirse de aquí y de allá, debe entenderse en relación con la idea de identidad fluida que comentábamos anteriormente. En esta línea, Levitt y Glick (2004: 62) afirman que «la incorporación de los migrantes a una nueva tierra y las conexiones transnacionales con un terruño o con redes dispersas de familiares, compatriotas o personas con las que se comparte 
una identidad religiosa o étnica, pueden darse al mismo tiempo y reforzarse entre sí». Es decir, esta simultaneidad identitaria refleja, en este caso, que en la construcción de la identidad de estos jóvenes se incorporan elementos de dos culturas diferentes. Cada persona, no obstante, priorizará unos elementos $\mathrm{u}$ otros, formando jerarquías particulares que dan lugar a diversos niveles de identificación.

Dado que la identidad está en constante construcción, las experiencias de vida de estos jóvenes influyen de manera directa en este proceso, y su entorno más directo encaminará la incorporación de unos u otros elementos. El círculo de amistades protagonizado por personas de su misma procedencia refuerza una identidad marroquí que se mantiene para asegurar su pertenencia a un grupo concreto: el de jóvenes marroquíes. En relación con ello, Levitt y Glick (2004) sostienen que existen varias diferencias entre las formas de ser y las formas de pertenecer a una sociedad o a un campo social. Las formas de ser se refieren a «las relaciones y prácticas sociales existentes en la realidad, en las que participan los individuos» (2004: 68). Es decir, estos jóvenes se han incorporado a un nuevo entorno, a una nueva realidad social en donde existen diversas categorías identificativas a las que eligen si adscribirse o no. No obstante, el simple hecho de estar incorporado en dicho campo social no implica que una persona se reconozca en todos los ámbitos lindantes. Por otra parte, las formas de pertenecer se refieren a «las prácticas que apuntan o actualizan una identidad, que demuestran un contacto consciente con un grupo específico» (2004: 68). Es decir, son aquellas acciones que refuerzan nuestra identidad o nuestra pertenencia a un grupo; en este caso, los círculos íntimos de amistad reflejan un claro sentimiento de pertenencia a un grupo con el que comparten experiencia migratoria y procedencia.

El análisis de redes permite visualizar de una manera clara las relaciones personales de cada informante. Esta técnica me sirvió para complementar la información recogida a través de las entrevistas en profundidad, ya que, como apuntan Maya-Jariego, Cachia, Holgado y Ramos (2014: 10), «la visualización de una red puede servir para obtener nueva información». Decidí utilizar el análisis de redes porque aporta una información directa y visual, y porque mediante la visualización de redes se facilita la comprensión de la composición y la estructura del mundo social de las personas, resumiendo los grupos y personas de referencia. No se trata, por lo tanto, de confirmar o desmentir la 
información recogida mediante la técnica anterior, sino de tener otro recurso, de carácter más sintético y visible, que complemente la información ya obtenida mediante las entrevistas.

El programa elegido para la realización de los grafos ha sido Ucinet 6/NetDraw, una herramienta computacional en el análisis de redes. Mediante estos grafos, todos de edición propia, podemos observar qué personas forman parte de las redes personales de los entrevistados, cuál es el ámbito o dónde se conocieron, e incluso la intensidad de la relación. En general, las redes se conforman de personas de su misma procedencia (marroquíes). El tiempo de estancia en Tortosa establece algunas diferencias en la composición de las redes, que, como vemos en la red de Jibril, tiene una composición más heterogénea, donde se combinan personas tanto de su misma procedencia como autóctonas. Por eso, el tiempo de residencia en Tortosa permite y facilita un mayor contacto con las personas autóctonas y, así, tener una red personal mucho más heterogénea.

A pesar de llevar prácticamente la mitad de sus vidas aquí, sus vínculos más fuertes los tienen con personas con las que comparten procedencia, costumbres y prácticas. Se podría añadir, además, que el paso por el aula de acogida favorece las relaciones entre personas con características similares y no tanto con el resto del alumnado. A medida que pasa el tiempo de residencia, no obstante, los jóvenes relatan que su círculo de amistades no ha cambiado mucho, por lo que la red de los jóvenes no varía mucho en su composición y siguen siendo las personas con las que comparten la misma experiencia migratoria y procedencia quienes articulan gran parte de la red. 
Gráfico 1: Red personal de Jibril

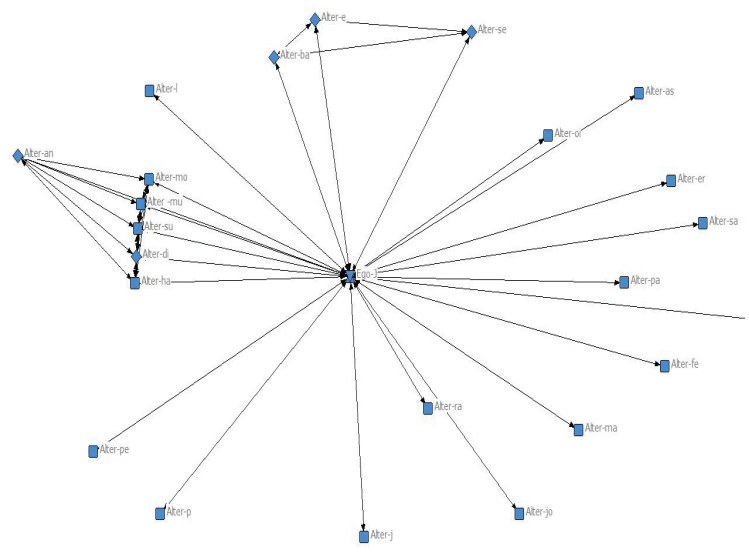

Gráfico 2: Red personal de Moha

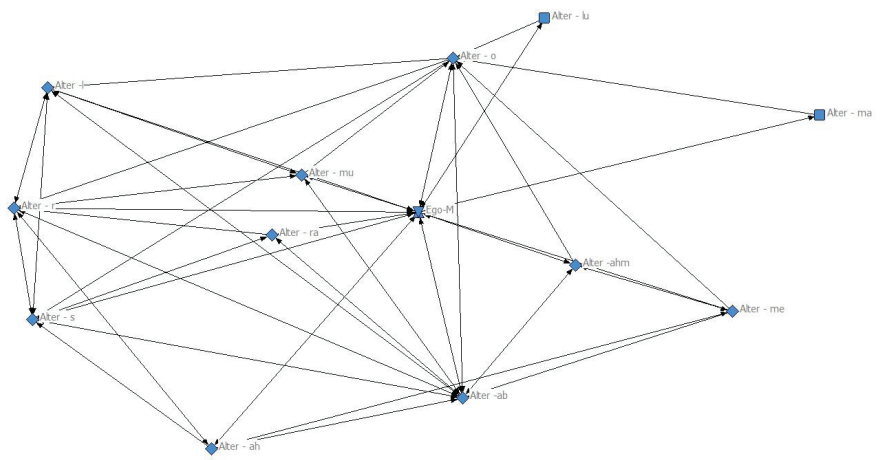




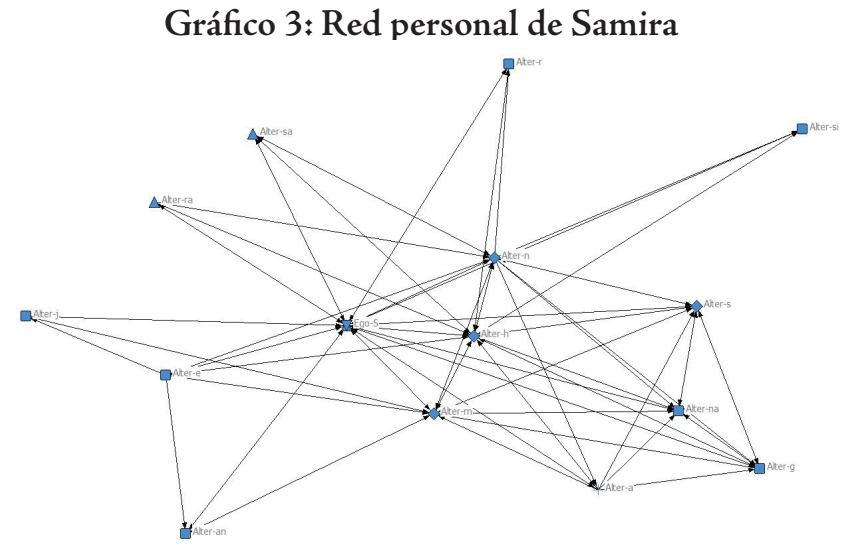

Gráfico 4: Red personal de Nadia

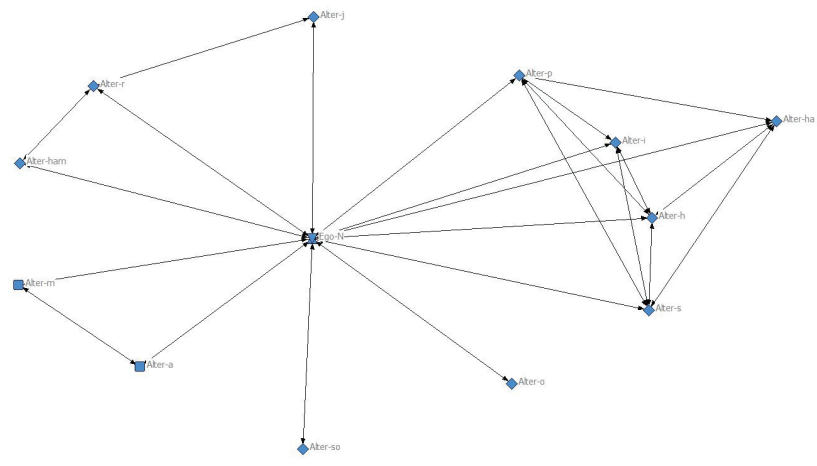

\begin{tabular}{|c|c|c|c|c|}
\hline$\square$ & $\square$ & $\diamond$ & + & $\Delta$ \\
\hline Ego & España & Marruecos & Ecuador & Francia \\
\hline
\end{tabular}

La composición de las redes según el ámbito aporta información relacionada con el origen de la relación. Si bien las relaciones formadas en el colegio están presentes en todas las redes, encontramos diferentes áreas y espacios significativos para los entrevistados, ya sean la familia, el trabajo, su presencia en alguna organización u otro tipo de entornos. Esto, por supuesto, está condicionado y varía según el tiempo libre que tengan para dedicarlo a otros entornos que no sean la casa o el colegio, como apuntan en su mayoría las chicas. 
Se observa, por lo tanto, diferencias significativas relacionadas con la composición de la red según el ámbito y origen de las relaciones entre chicos y chicas:

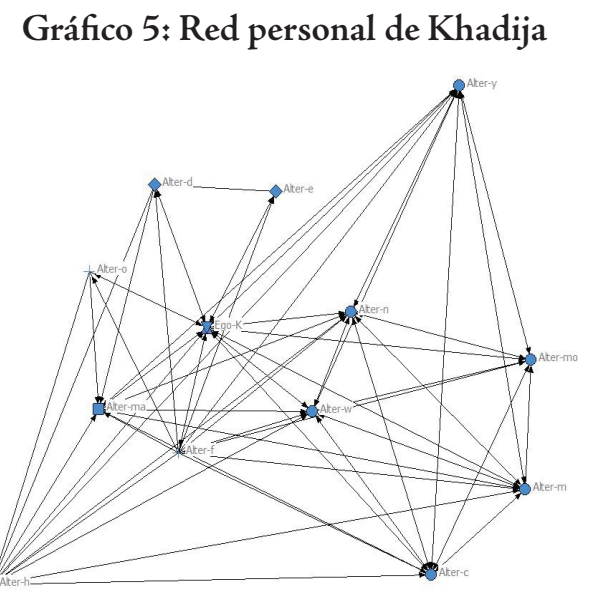

\section{Gráfico 6: Red personal de Jibril}

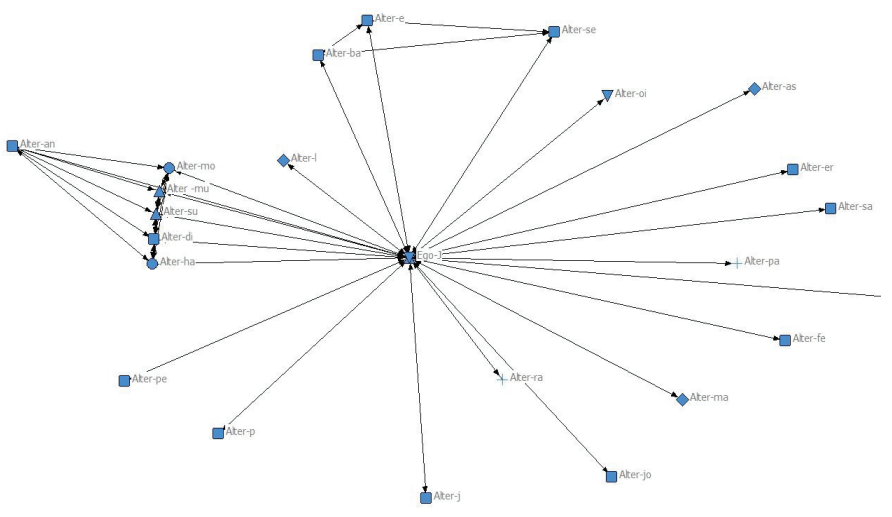

\begin{tabular}{|l|c|c|c|c|}
\hline $\mathbf{Q}$ & $\square$ & 0 & $\Delta$ & + \\
\hline Ego & Organizaciones & Familia & Otra familia & Otros \\
\hline
\end{tabular}


En general, las personas autóctonas presentes en las redes se caracterizan por formar parte o bien del ámbito de las organizaciones, o bien del laboral. En esta línea, observamos claras diferencias entre ambas redes, que ponen de manifiesto la vida social y dónde se emplea el rato libre, lo cual influye en la propia composición de la red, porque no descubren los mismos entornos.

La configuración de las redes, por otro lado, es diversa. Como apuntan desde la Fundación EDE, «las redes segmentadas se caracterizan por tener un amplio número de personas, las cuales se distribuyen claramente en distintos grupos que suelen corresponder con los diferentes espacios en los que las personas entrevistadas desarrollan las actividades de la vida diaria (el colegio o el trabajo, la casa, el recurso formal, etc.). En el caso de las redes concentradas existe una mayor relación entre las personas que conforman la red (aunque no entre todas), de manera que la red está más agrupada y no existen grupos independientes unos de otros aunque puedan percibirse subgrupos interconectados entre sí» $(2011: 40)$.

En este sentido, observamos que, a pesar de que la red de Jibril esté constituida por ámbitos más diversos, es mucho más segmentada que la de Khadija, quien se mueve por menos entornos pero con relaciones más densas, es decir, las personas que conforman su red, al limitarse a espacios concretos, se conocen.

\section{Algunas reflexiones finales}

Si analizamos las experiencias de vida y las trayectorias de los jóvenes, podemos confirmar que la migración desempeña un papel importante en el día a día de estos jóvenes y en su forma de percibir y vivir la realidad. Tras una primera migración encaminada por el padre en busca de un futuro mejor, estos jóvenes llegan aquí gracias a una reagrupación familiar y cambian de lugar de residencia sin formar parte activa de esa decisión migratoria. Una vez asentados en este nuevo entorno, sus experiencias vitales van caminando entre dos formas de ver, sentir y percibir la vida: por un lado, sus padres siguen manteniendo prácticas, costumbres y valores de su país de origen, que pasarán a los hijos por diversos motivos, generalmente pensando en un posible retorno a Marruecos; por otro lado, estos jóvenes incorporan nuevos elementos y valores propios de nuestra sociedad. La visión del mundo de estos jóvenes, por lo tanto, se conforma tras la adhesión de elementos de ambas culturas, que darán a cada uno su manera particular de sentir y vivir su vida cotidiana. 
Desde una lógica parecida, encontramos la forma en que estos jóvenes construyen su identidad. Pese a llevar la mayor parte de sus vidas viviendo en Tortosa, la mayoría tiende a autoidentificarse como marroquí, lo cual refuerza un sentimiento de pertenencia hacia un grupo con cuyos miembros comparten misma experiencia migratoria y procedencia. Portes y Aparicio (2014) señalan, en esta línea, que las identidades adoptadas por los jóvenes y la estima que tengan de sí mismos influyen de manera consistente en su integración en la sociedad de recepción. No obstante, este tipo de autoidentificaciones no tiene por qué condicionar una integración positiva en Tortosa, al igual que la adopción de una identidad nacional del país de acogida tampoco garantiza una plena integración. Además, como afirman Portes y Aparicio (2014: 49), «la integración identitaria se complica cuando en la sociedad receptora existen delimitaciones fuertes de carácter étnico o racial»; es decir, las conductas y actitudes de los ciudadanos españoles influyen de manera decisiva en la posibilidad de una mayor integración. De esta manera, si los jóvenes perciben situaciones y comportamientos de rechazo y discriminación, tenderán a reforzar más los sentimientos de pertenencia y autoidentificación marroquí.

Si bien la construcción de la identidad es un proceso dinámico, este adquiere una mayor complejidad en la adolescencia y juventud. Feixa (1999: 18) sostiene que "para que exista la juventud, debe existir, por una parte, una serie de condiciones sociales (es decir, normas, comportamientos e instituciones que distingan a los jóvenes de otros grupos de edad) y, por otra parte, una serie de imágenes culturales (es decir, valores, atributos y ritos asociados específicamente a los jóvenes)». Además, ambas dependerían de la estructura social predominante en cada sociedad. Esta idea ayuda a entender las diferencias de las trayectorias de vida de los jóvenes entrevistados en relación con las dinámicas, actividades y percepciones vitales de los jóvenes autóctonos, ya que los valores y las responsabilidades adquiridas por unos y por otros difieren a niveles como el familiar y el social. Estas diferencias son más visibles aún en las chicas, quienes adoptan responsabilidades de diferente índole. Las jóvenes procedentes de Marruecos adoptan gran parte de las responsabilidades familiares, sobre todo en relación con el trabajo reproductivo, como cuidar a los hermanos menores o los hijos (Solé, Alcalde, Sordé, Petroff, 2013), mientras que las españolas, además de tener otras expectativas de futuro, no son educadas hacia este camino. Las diferencias en cuanto a los valores y responsabilidades de la 
juventud varían, por lo tanto, según cada cultura, por lo que, de una manera u otra, esto podría influir en la integración de los jóvenes en Tortosa.

Estos jóvenes constituyen un claro ejemplo de una realidad transformada y modificada como consecuencia del fenómeno migratorio, y son testigos principales de la creación de nuevas dinámicas sociales y relacionales entre recién llegados y autóctonos. En esta dimensión relacional, además, se establecen diversas formas de convivencia entre los habitantes de la ciudad, es decir, las relaciones interculturales que se establecen entre los ciudadanos desvelan el tipo de convivencia existente. Como veíamos en apartados anteriores, la pluralidad cultural se diluye en diversas formas del vivir cotidiano, conformando sociedades multiculturales o interculturales (Giménez, 2003). Mientras que las primeras aseguran un respeto a la diferencia cultural, las segundas van más allá y nacen a partir de las relaciones establecidas entre personas de diferentes culturas fomentando una convivencia positiva. Los relatos de jóvenes entrevistados y sus redes personales desvelan un estado de coexistencia en la ciudad, ya que las personas inmigradas y los autóctonos comparten y habitan la misma ciudad sin establecer relaciones de iguales entre sí. Además, remarcan un deseo de cambio que oscila entre ambos bandos, es decir, admiten que los chicos y chicas marroquíes deberían poner más de su parte en cuanto a aprender la lengua y relacionarse con vecinos y vecinas de la ciudad, y afirman que los chicos y chicas autóctonos adoptan un comportamiento de pasividad y a veces basado en estereotipos.

Para finalizar, es necesario subrayar que, a pesar de que los jóvenes entrevistados no conforman una muestra representativa en términos estadísticos de dicho colectivo poblacional, ya sea por el reducido número de informantes o por sus características, estos jóvenes y sus trayectorias de vida sí son significativos para comprender cómo influyen las experiencias de inmigración en su vida cotidiana. Para conocerlo, ha sido necesario poner en marcha técnicas que permitan descifrar y comprender las experiencias de vida de estos jóvenes desde sus propias voces, que nos acerquen a cómo viven y perciben la realidad. Es importante destacar que esta investigación supone una aproximación a un colectivo poblacional específico - jóvenes que han experimentado procesos familiares de inmigración- y que, sin afán de generalizar, muestra historias significativas para repensar y reflexionar sobre las consecuencias y el impacto de los procesos migratorios en quienes lo viven y experimentan. 


\section{Bibliografía}

Augé, M. (1993). Los no lugares: espacios del anonimato. Una antropología de la sobremodernidad. Barcelona: Gedisa.

- (1998). Hacia una antropología de los mundos contemporáneos. Barcelona: Gedisa.

Castells, M. (1998). La era de la información. Economía, sociedad y cultura. El poder de la identidad. Madrid: Alianza.

Clifford, J. (1999). Itinerarios transculturales. Barcelona: Gedisa.

Corbetta, P. (2007). Metodología y técnicas de investigación social. Madrid: McGraw- Hill.

Fundación EDE (2011). Relaciones de solidaridad entre inmigrantes: acercamiento a las redes informales de apoyo de menores y jóvenes no acompañados en la CAPV. Recuperado el 17 de marzo de 2016, de <http://www.fundacionede.org/ca/archivos/investigacionsocial/experiencias-solidaridadjovenes-extranjeros-acompanados-08012013.pdf > .

García Canclini, N. (1990). Culturas hibridas. Estrategias para entrar y salir de la modernidad. México: Grijalbo.

García, I. (2003). «Los hijos de inmigrantes como tema sociológico: la cuestión de la 'segunda generación'». Anduli: Revista andaluza de ciencias sociales, $n .^{\circ}$ 3, 27-46.

García, R. (2003). «Un estado de la cuestión de las teorías de las migraciones.» Revista de Historia Contemporánea, n+* 26.

Geertz, C. (2003). La interpretación de las culturas. Barcelona: Gedisa.

Giménez, G. (1997). «Materiales para una teoría de las identidades sociales.» Revista Frontera Norte, vol. 9, n. ${ }^{\circ} 18$.

Giménez, C. (2003). «Pluralismo, multiculturalismo e interculturalidad.» Revista de Educación y Futuro: Revista de Investigación Aplicada y Experiencias educativas, n+ ${ }^{\circ}$ 8, 9-26.

Hannerz, U. (1997). Conexiones transnacionales. Cultura, gente, lugares. Valencia: Cátedra y Universitat de València.

Juliano, D. (2002). «Los desafíos de la migración. Antropología, educación e interculturalidad.» Anuario de Psicología, vol. 33, n. 4, 487-498. 
LAсомва, J. (2001). «Teorías y prácticas de la inmigración. De los modelos explicativos a los relatos y proyectos migratorios.» Revista Electrónica de Geografía y Ciencias Sociales, n. ${ }^{\circ} 94$.

Levitt, P. y Glick, N. (2004). «Perspectivas internacionales sobre migración: conceptuar la simultaneidad.» Migración y desarrollo, n. ${ }^{\circ}$ 3, 60-91.

Manlouf, A. (1998). Identidades asesinas. Madrid: Alianza Editorial.

Mendizábal, N. (2006). «Los componentes del diseño flexible en la investigación cualitativa.» Estrategias de investigación cualitativa. Herramientas de educación, 65-103.

Pujadas, J.; Comas, D.; Roca, J. (2010). Etnografía. Barcelona: UOC.

Portes, A. y Aparicio, R. (2014). Crecer en España. La integración de los bijos de inmigrantes. Colección Estudios Sociales de La Caixa, n+ 38.

Solé, C.; Alcalde, R.; Sordé, T.; Petroff, A. (2013). «Hijos e hijas de inmigrantes: gestión de la interculturalidad para la cohesión social.»CERM, Universidad Autónoma de Barcelona.

Valles, M. (1999). Técnicas cualitativas de investigación social. Reflexión metodológica y práctica profesional. Madrid: Síntesis. 